\title{
ENTOMOLOGY
}

\section{Persistency of Chlorpyrifos and Termiban (Imidacloprid) in soil against subterranean termites}

\author{
B. Hassan, ${ }^{1}$ S. Ahmed, ${ }^{1}$ M.A. Ejaz ${ }^{2}$ \\ ${ }^{1}$ Termite Research Laboratory, Department of Entomology, University of Agriculture, Faisalabad; ${ }^{2}$ Tara Group ${ }^{\mathrm{TM}}$, \\ Pakistan, Chunnia bypass road Raiwand, Raiwind, Lahore, Kasur, Punjab, Pakistan
}

\begin{abstract}
Subterranean termites are considered to be one of the most destructive termites in urban areas in Pakistan. Different types of insecticides have been used to control subterranean termites. The present studies were conducted to evaluate the comparative persistency and effectiveness of Termiban (imidacloprid 5 SC) and Chlorpyrifos (40 EC) against subterranean termites in the three type of soils (sand, silt and clay) at different time interval. Two different concentrations (100 and $200 \mathrm{ppm}$ ) of selected insecticides were prepared and applied to soil in petri plates and termite were released at different time interval to record mortality. Results showed that at each time interval and concentration, mortality of termite was non-significantly different for both insecticides. When persistency of insecticides was tested under closed condition, results showed that lowest weight loss $(8.60 \%)$ of wood was observed in Termiban treated soil at $200 \mathrm{ppm}$ which was significant different from rest of the treatments. Similarly, under open
\end{abstract}

Correspondence: Babar Hassan, Termite Research Laboratory, Department of Entomology, University of Agriculture, Agriculture, University Road, Faisalabad 38000, Pakistan.

Tel.: +92.3377105236

E-mail: sialuaf@gmail.com

Key words: Termiticides, persistence, soil barrier, subterranean termites.

Contributions: the authors contributed equally.

Conflict of interests: the authors declare no potential conflict of interests.

Funding: none.

Received for publication: 2 August 2018

Revision received: 2 September 2018.

Accepted for publication: 2 September 2018.

CCopyright B. Hassan et al., 2018

Licensee PAGEPress, Italy

Journal of Entomological and Acarological Research 2018; 50:7735

doi:10.4081/jear.2018.7735

This article is distributed under the terms of the Creative Commons Attribution Noncommercial License (by-nc 4.0) which permits any noncommercial use, distribution, and reproduction in any medium, provided the original author(s) and source are credited. conditions, at each time interval, there was significant more mortality of termites in soil treated with Termiban compared to Chlorpyrifos.

\section{Introduction}

Soil barrier is an effective mean to arrest march of termites towards valuables in household and buildings (Nunes \& Nobre, 2001; Ahmed et al., 2006; Ahmed \& Qasim, 2011). Besides other non-chemical materials, insecticides such as chlorpyrifos, bifenthrin and fipronil have been commonly advocated for pre-or post-construction barriers in the soil (Aihetesham et al. 2018). Chlorpyrifos in generic form Termikill and several other trade names or brand such as Dursban, Boimax, and Larsban has been extensively used as termiticide for the last two decades in Pakistan (Manzoor \& Pervez, 2014, Sohail et al. 2015). Later fipronil (Regent 5\% SC) was introduced as non-repellent termiticide along with bifenthrin (Biflex TC) as repellent termiticide and these two are popular with constructors (Manzoor et al., 2012; Saljoqi et al. 2014).

Insect IGRs such as fenoxycarb, hexaflumuron, flufenoxuron, sulfarmide and diflubenzuron reported elsewhere as ingredient in a termite bait (Kakkar et al., 2018) are not popular as a soil application in Pakistan, though few laboratory studies have been conducted to determine efficacy against one important species of pesttermite, Heterotermes indicola (Isoptera: Rhinotermitidae) (Misbah-ul-Haq et al., 2015; Misbah-ul-Haq \& Khan, 2015). Now a days, newer chemicals such as imidacloprid and fipronil are gaining acceptance as termiticides compared to pyrethroids and organophosphate insecticides (Haverty \& Sunden-Bylehn, 2000). Imidacloprid has been popularized for long term protection in terms of Perimeter Protocol owing reduction of active ingredient use for this purpose and inherently provision of advantage to reduce potentials for exposure to applicators and residents alike (Reid et al., 2002; Hendersen et al., 2016). It has proven to provide residual control of termites ranging from 5 to more than 10 years in Japan, North America, South Africa and Australia (Byron et al., 2002). Recent infestation of termites belonging to family Termitidae and Rhinotermitidae is the result of overwhelming urbanization in Pakistan demands protection of structures from termites with chemicals having persistency and efficacy. Keeping the importance of imidacloprid, the current experiment was performed to determine comparative persistency and effectiveness of Termiban (a new formulation of imidacloprid 5 SC) and chlorpyrifos (40 EC) against subterranean termites in the soils. 


\section{Materials and Methods}

\section{Study site}

The experiment was conducted in Entomological Research Laboratories (ERL), Post Agriculture Research Station (PARS), Jhang Road Faisalabad and in Termite Research Laboratory, Department of Entomology, University of Agriculture, Faisalabad, Pakistan.

\section{Collection of termites}

Subterranean termites were collected from non-vegetated agricultural fields around Entomological Research Laboratories (ERL), PARS, Jhang Road Faisalabad by using underground traps. Traps were consisted of polyvinyl chloride (PVC) pipes having 60 $\mathrm{cm}$ length and $10 \mathrm{~cm}$ diameter which were buried in the soil with the top $2 \mathrm{~cm}$ above the soil. A roll of $100 \mathrm{~g}$ moistened, corrugated card board was placed inside the pipes and were capped. Polythene bags were used to transfer infested cardboard rolls with termites to the laboratory (Ahmed et al., 2006).

\section{Efficacy of termiticides}

Three different types of soils (sand, loam and clay) were collected and sieved to remove debris and were sterilized in an Autoclave. A total of $10 \mathrm{~g}$ of each soil was placed in petri plates separately and distilled water was used to moisten the soil. Two concentrations (100 and $200 \mathrm{ppm}$ ) of each imidacloprid (Termiban 5\% SC) and chlorpyrifos (Chlorpyrifos 40EC) were prepared using distilled water. Five millimeters of each concentrations were used to treat soil in petri plates. A total of 100 workers and 10 soldiers of termites were exposed to the soils and data on mortality of termites were recorded after 2, 4, 6, 8, 10 and 12 weeks. A set of petri plates having soil were also treated with distilled water only to serve as control treatment. The test was replicated three times by using Completely Randomized Design (CRD).

\section{Persistency of termiticides under closed conditions}

Two concentrations of both imidacloprid and chlorpyrifos were sprayed on the surface of the prepared plots $(0.6 \times 0.3 \mathrm{~m}$ dimension) and covered with PVC sheets under two factorial Randomized Complete Block Design (RCBD). Concrete of $8 \mathrm{~cm}$ thickness was poured on PVC sheet leaving the area around PVC pipes. PVC sheets were removed from inside the PVC pipes. Wood blocks of Populus deltoids $(2 \times 3 \times 5 \mathrm{~cm})$ were placed inside the PVC pipes that were capped. Data regarding wood weight loss were recorded after 4, 8, 12, 16, 20 and 24 weeks.

\section{Persistency of termiticides in open conditions}

The experiment was conducted in selected buildings of different farm houses. Three farm buildings were selected and chemicals applied at maximum field recommend rates. First room was treated with imidacloprid; second room with chlorpyrifos and third was kept as control. After 8, 16 and 24 weeks, soil was taken at the depth of $15 \mathrm{~cm}$ and bioassay was performed in the laboratory by exposing 100 termite workers and 10 soldiers to the soil in petri plates having $10 \mathrm{~g}$ of soil each.

\section{Statistical analysis}

Corrected mortalities were calculated from Abbot's formula (1925). Interaction of concentrations time and soils in experiment No. 1 were found from three-way ANOVA. Weight loss differences were calculated from three Way ANOVA while differences in mean moralities in experiment No. 3 were analyzed by One-way ANOVA at $\mathrm{P}<0.05$.

\section{Results}

Efficacy of two concentrations (100 and $200 \mathrm{ppm}$ ) of imidacloprid (Termiban 5\% SC) and chlorpyrifos (Chlorpyrifos 40EC) in three different types of soils (sand, loam and clay) were determined after 2, 4, 6, 8, 10 and 12 weeks after exposure of termites. At each time interval, interaction of concentrations in three different soils in terms of mortality of termites was found to be non-significant $(\mathrm{P}>0.05)$ at different time intervals (data not shown).

Weight losses of wooden stakes when persistency of insecticides was tested under closed condition is shown in Table 1. Termiban and chlorpyrifos at $100 \mathrm{ppm}$ had non-significant difference between each other at each time interval. Weight losses in Termiban and chlorpyrifos treatments were significantly different at 4, 8 and 12 weeks after exposure and beyond this time period, weight losses in both the termiticides treated soils at $200 \mathrm{ppm}$ had significant difference $(\mathrm{p}>0.05)$. Lowest weight loss $(8.60 \%)$ was observed in Termiban treated soil at $200 \mathrm{ppm}$ which was significant different from rest of the treatments.

\section{Discussion and Conclusions}

Termiban and chlorpyrifos showed significant difference in mortalities of termites in soil sampled at three time period after

Table 1. Weight loss of treated wooden stakes with chlorpyrifos and Termiban at various time intervals.

\begin{tabular}{lllll} 
Time intervals(weeks) & \multicolumn{2}{c}{ Chlorpyrifos } & \multicolumn{2}{c}{ Termiban } \\
& $100 \mathrm{ppm}$ & $200 \mathrm{ppm}$ & $100 \mathrm{ppm}$ & $200 \mathrm{ppm}$ \\
4 & $31.4 \pm 0.89^{\mathrm{a}}$ & $14.00 \pm 0.84^{\mathrm{b}}$ & $28.6 \pm 2.02^{\mathrm{a}}$ & $8.60 \pm 1.40^{\mathrm{c}}$ \\
8 & $27.8 \pm 2.16^{\mathrm{a}}$ & $26.0 \pm 1.03^{\mathrm{a}}$ & $28.4 \pm 2.08^{\mathrm{a}}$ & $18.2 \pm 1.75^{\mathrm{b}}$ \\
\hline 12 & $28.2 \pm 1.75^{\mathrm{a}}$ & $30.8 \pm 1.58^{\mathrm{a}}$ & $29.4 \pm 1.98^{\mathrm{a}}$ & $15.0 \pm 1.0^{\mathrm{b}}$ \\
16 & $69.6 \pm 2.12^{\mathrm{a}}$ & $29.2 \pm 1.89^{\mathrm{b}}$ & $67.6 \pm 1.71^{\mathrm{a}}$ & $28.8 \pm 1.84^{\mathrm{b}}$ \\
\hline 20 & $69.8 \pm 1.80^{\mathrm{a}}$ & $50.6 \pm 2.19^{\mathrm{b}}$ & $67.2 \pm 1.04^{\mathrm{a}}$ & $49.6 \pm 1.71^{\mathrm{b}}$ \\
24 & $90.2 \pm 2.18^{\mathrm{a}}$ & $51.0 \pm 2.46^{\mathrm{b}}$ & $88.8 \pm 2.15^{\mathrm{a}}$ & $48.8 \pm 2.46^{\mathrm{b}}$ \\
\hline
\end{tabular}

Values are means \pm SE. Means sharing same letters in columns and rows are not significantly different from one another at $p<0.05$. 


\section{$\mathbb{B}$ chlorpyrifos $\quad$ TTermiban}

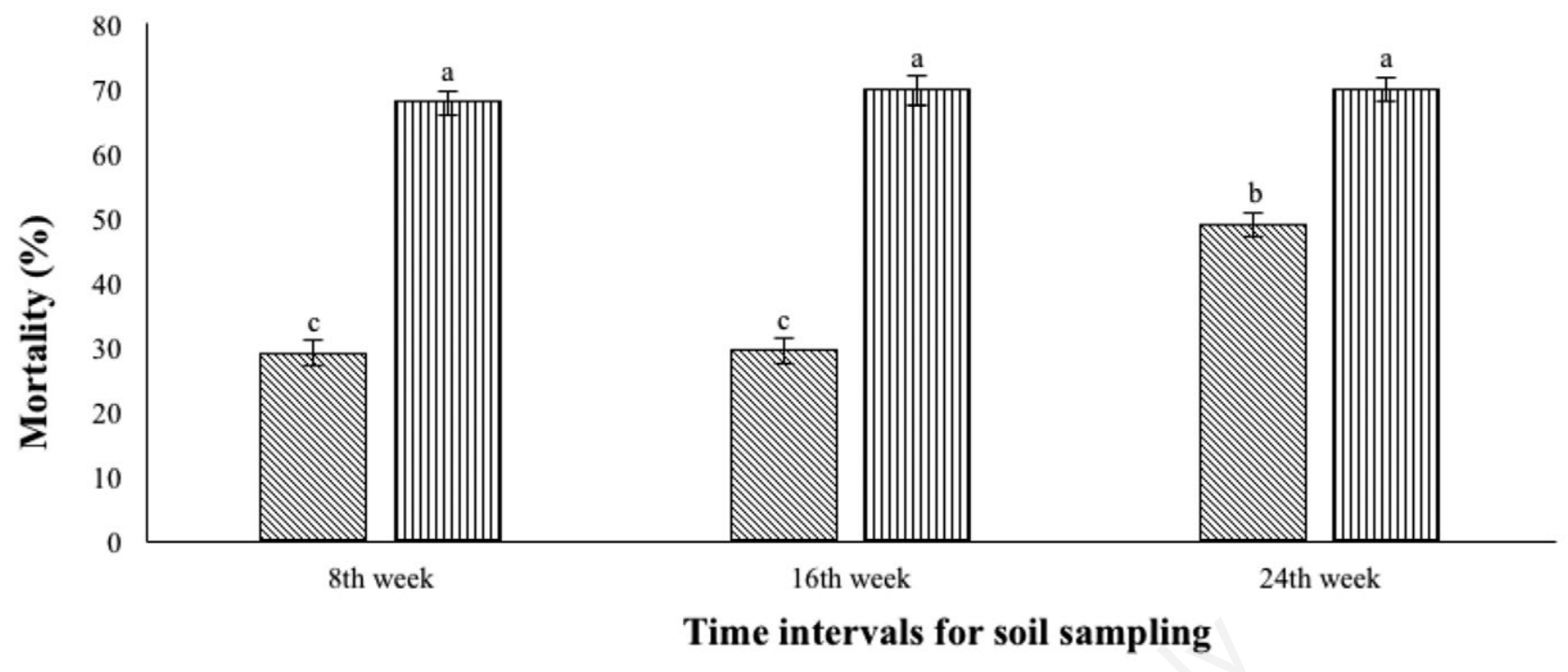

Figure 1. Mortality of termites (\%) in treated soils of different time periods.

application in open conditions. At each time interval, there was significant more mortality of termites in soil treated with Termiban as compared to the soil treated with Chlorpyrifos. Chlorpyrifos showed significant increase in morality at $24^{\text {th }}$ week sampled soil as compared to other two-time intervals. However, Termiban maintained a relatively constant effect on termites and mortalities were in narrow range at three time periods (Figure 1).

The present studies revealed that Termiban is an effective termiticide and can be comparable with popular and commonly available Chlorpyrifos $40 \mathrm{EC}$ which has been used generally in the past until recently. Chlorpyrifos $40 \mathrm{EC}$ at $1-2$ Liter per $140 \mathrm{ft}^{2}$ is recommended by household pest operator in Pakistan. Chlorpyrifos is also reference insecticide and is usually included in bioassay for comparison with other intended termiticide (Ahmed et al., 2006; Ahmed et al., 2017; Ahmed \& Qasim, 2011; Manzoor et al., 2012; Saljoqi et al., 2014; Manzoor \& Pervez, 2014, Sohail et al., 2015). Chlorpyrifos still holds effectiveness against all kinds of termites in and around structures and in agricultural fields as well, while countries, like Europe and USA, have now superseded its uses (Haverty \& Sunden-Bylehn, 2000). Laboratory trials showed termites' mortality from chlorpyrifos treated soil in just 24 hours which is species specific and concentration dependent (Manzoor \& Pervez, 2014; Misbah-ul-Haq et al., 2015; Misbah ul Haq \& Khan, 2015). Chlorpyrifos is repellent termiticide and prevent termites' movement in soil and thus limit access to food which causes mortality (Ahmed et al., 2015). Chlorpyrifos is being reassessed in a number of countries including the European Union, New Zealand, and the USA.

Previously, imidacloprid has been successfully used to achieve structural protection (78.6\%) with only a single, follow-up 'spot' application (Reid et al., 2002). In some other studies, topical application of the insecticides on the termites showed the following order of efficacy: chlorpyrifos $>$ bifenthrin $>$ flufenoxuron $>$ thiamethoxam > imidacloprid (Ahmed et al., 2006). The latter may appear slow acting termiticide (Rasib et al., 2018), nevertheless, contact was once and residual action is not perceived in topical application. However, in another study, Rasib et al. (2017) found imidacloprid to be is more toxic than fipronil based on $\mathrm{LC}_{50}$ values. Since imidacloprid has been established as an effective termiticide either as barrier or bait application against termites (Iqbal \& Evans, 2018), replacement of chlorpyrifos with imidacloprid is therefore concluded.

\section{References}

AHMED M.A.I., ERAKY El-S. A., MOHAMED M.F., SOLIMAN A.A.S., 2015 - Potential toxicity assessment of novel selected pesticides against sand termite, Psammotermes hypostoma Desneux workers (Isoptera: Rhinotermitidae) under field conditions in Egypt. - J. Pl. Protect. Res. 55: 193-197.

AHMED S., QASIM M., 2011- Foraging and chemical control of subterranean termites in a farm building at Faisalabad, Pakistan. - Pak. J. Life Soc. Sci. 9: 58-62.

AHMED S., HASSAN B., YAQOOB M.M., NISAR M.S. RASHID A., 2017 - Efficacy of Chlorpyrifos and Fipronil in relation to soil depths against Subterranean Termites. - J. Entomol. Acarol. Res. 49: 6386.

AHMED S., RIAZ M.A., SHAHID M., 2006 - Response of Microtermes obesi (Isoptera: Termitidae) and its gut bacteria towards some plant extracts.- J. Food Agric. Environ., 4: 317-320.

AIHETESHAM A., AKHTAR M.S., BIBI T., BODLA I., 2018 Efficacy of Biomax and Fiprokill against Heterotermes indicola (Wasmann). - Asian J Agri. Biol. 6: 90-94.

HAVERTY M., SUNDEN-BYLEHN A., 2000 - Finding alternatives to persistent organic pollutants (POPs) for termite management. International Activities on Persistent Organic Pollutants (POPs) covered by the Stockholm Convention. Stockholm, Sweden.

IQBAL N., EVANS T.A. 2018 - Evaluation of fipronil and imida- 
cloprid as bait active ingredients against fungus-growing termites (Blattodea: Termitidae: Macrotermitinae). - Bull. Ento. Res. 108: 14-22.

KAKKAR G., OSBRINK W., SU N.Y., 2018 - Molting site fidelity accounts for colony elimination of the Formosan subterranean termites (Isoptera: Rhinotermitidae) by chitin synthesis inhibitor baits. - Sci. Rep. 8: 1259.

MANZOOR F., SAYYAD A.H., RAFIQUE T., MALIK S.A., 2012 - Toxicity and repellency of different insecticides against Heterotermes indicola (Isoptera: Rhinotermitidae). - J. Anim. P1. Sci. 22: 65-71.

MANZOOR F., PERVEZ M., 2014 - Efficacy of Biflex and Fipronil in controlling subterranean termites (Isoptera: Rhinotermitidae) in different soils types in Pakistan. Proceedings of the $10^{\text {th }}$ Pacific-Termite Research Group Conference, Forschler, B.T. (ed.)

MISBAH UL HAQ M., KHAN I.A. 2015 - Study of trail-following behavior of subterranean termite, Heterotermes indicola (Isoptera: Rhinotermitidae) after exposure to various concentrations of insect growth regulators. - J. Entomol. Zool. Stud. 3: 406-411.

MISBAH-UL-HAQ M., KHAN I.A., FARID A., ULLAH M., ALAMZEB, 2015 - Dose response relationship of subterranean termite, Heterotermes indicola (Wasmann) and two insect growth regulators, Hexaflumuron and Lufenuron. - J. Entomol. Zool. Stud, 3: 86-90

NUNES L., NOBRE T., 2001. Strategies of subterranean termite control in buildings. In: Historical Constructions, Lourenço,
P.B. and P. Roca (Eds.), Guimarães, pp. 867-874. Proceed. $0^{\text {th }}$ Pacific-Termite Res. Group Conf., S 4.1:3.

RASIB K.Z., AIHETESHAM A., ARIF H., AFZAL M., 2018 Effect of Sub lethal concentrations on population size of termites Odontotermes obesus (Rambur) and Coptotermes heimi (Wasmann) under laboratory and field conditions. - Biomed J. Sci. Tech. Res. 3: 1-7.

RASIB K.Z., HIDAYAT W., AIHETASHAM A., 2017 - Feeding preferences and control of a Pakistani termite Odontotermes obesus (Rambur) (Isoptera, Rhinotermitidae. - Ann. Res. Revi. Biol. 18: 1-13.

REID B.L., BRINKMANN R., SMITH G., ISHIZAKA K., PALIS B., DEVILLIERS V., 2002 - Imidacloprid use in termite control operations globally and changing use patterns in the United States. In: Proceed. $4^{\text {th }}$ Intern. Conf. Urban Pests, Charleston, SC, USA, 7-10 July. Jones, S.C., J. Zhai, W.H. Robinson (Eds.), Pocahontas Press: Blacksburg, VA, USA, pp. 355-368.

SALJOQI A-UR-R., MUHAMMAD N., KHAN I.A., REHMAN S., NADEEM M., SALIM M., 2014 - Effect of different insecticides against termites, Heterotermes indicola L. (Isoptera: Termitidae) as slow acting toxicants. - Sarhad J. Agric. 30: 333-339.

SOHAIL K., KHAN I.A., MISBAH UL HAQ M., USMAN M., SHAH S.F., MEHMOOD A., IQBAL T., FAKHRUDDIN M., 2015 - Insecticidal studies on Heterotermis indicola Wasmann (Isoptera: Heterotermitidae) under laboratory conditions. - J. Entomol. Zool. Stud. 3: 348-350. 